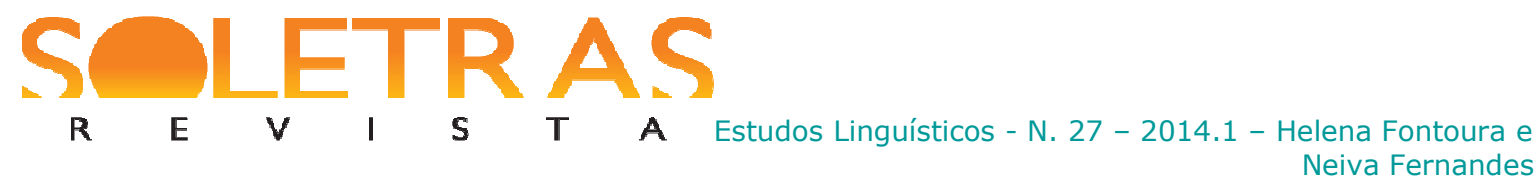

\title{
Quem quer ser professor/a? Contribuições de um estudo com licenciandos da Faculdade de Formação de Professores da Universidade do Estado do Rio de Janeiro
}

\author{
Helena Fontoura ${ }^{1}$ \\ Universidade do Estado do Rio de Janeiro / FFP \\ Neiva Santos Masson Fernandes ${ }^{2}$ \\ Mestre em Educação pela Faculdade de Formação de Professores da UERJ
}

\begin{abstract}
Resumo: Este artigo apresenta alguns dos resultados de uma investigação realizada no Mestrado em Educação com alunos dos cursos de licenciatura da Faculdade de Formação de Professores (FFP) da Universidade do Estado do Rio de Janeiro (UERJ): as características de seu perfil, as motivações para o seu ingresso em cursos de formação para o exercício do magistério e sua pretensão quanto a exercer a profissão docente. Foram convidados a participar da pesquisa os estudantes inscritos em períodos específicos, com a intenção de abranger alunos ingressantes, de meio de curso e concluintes de cada um dos cursos da instituição. Paulo Freire, António Nóvoa, Maurice Tardif, Bernardete Gatti e Elba de Sá Barreto são alguns dos autores que embasaram nossa investigação. Nessa pesquisa exploratória, de caráter quali-quantitativo, utilizamos questionários como instrumento de coleta de dados. Ao todo, 450 licenciandos participaram no estudo. A partir do que foi conhecido, das análises e reflexões construídas, buscamos contribuir para que a FFP/UERJ tenha novos subsídios para embasamento do processo de construção de seu Projeto PolíticoPedagógico, possibilitando aprimorar seus objetivos e suas metas, o que nos parece relevante no sentido de favorecer a reflexão e as ações propositivas no campo da formação inicial de professores e professoras na instituição.
\end{abstract}

Palavras chave: Profissão docente. Escolha profissional. Licenciatura.

Embora seja reconhecida a importância do professor na construção da sociedade atual, o exercício da docência atravessa um período de desprestígio social. Para Barreto (2010), a crise

\footnotetext{
${ }^{1}$ Graduada em Pedagogia pela Pontifícia Universidade Católica do Rio de Janeiro (1974); Graduate Diploma em Educational Psychology pela University of Alberta, Canada (1977); Mestre em Educação pela Universidade do Estado do Rio de Janeiro (1993); Doutora em Ciências pela Escola Nacional de Saúde Pública ENSP/Fundação Oswaldo Cruz (1997) e Pós Doutora em Educação na Universidade de Barcelona (2007). Professora Associada do Departamento de Educação da Faculdade de Formação de Professores da Universidade do Estado do Rio de Janeiro. É Bolsista do Programa Prociência da UERJ desde 2006. Tem grande experiência na área de Educação, com ênfase em Formação de Professores, atuando principalmente nos seguintes temas: formação de professores, estágio supervisionado, estudo de egressos, etnografia e análise de vídeo. Docente permanente do Mestrado em Educação: processos formativos e desigualdades sociais, da Faculdade de Formação de Professores (FFP/UERJ) de São Gonçalo. Pesquisadora 2 CNPq. Professora Colaboradora do Programa de Pós Graduação em Biociências e Ensino de Ciências (EBS) Fiocruz.

${ }^{2}$ Graduada em Letras pela Universidade Federal Fluminense (1988), com especialização em Língua Portuguesa pela mesma instituição (1991) e mestrado pela Universidade do Estado do Rio de Janeiro (2013). Atualmente, é Professor - Docente I da Prefeitura Municipal de São Gonçalo e Técnica em Assuntos Educacionais da Universidade Federal Fluminense.
} 


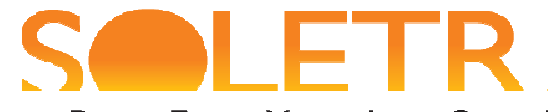

$\mathbf{R}$

na escola origina-se tanto da diminuição do valor relativo dos certificados que ela fornece como na perda do monopólio sobre a transmissão do saber autorizado. Souza (2011) chama a atenção de que essa desvalorização do diploma atinge, principalmente, o certificado conquistado pelos licenciados, expedido pelas instituições formadoras. Contrariando esse cenário pouco atraente, muitos estudantes, concluído o ensino médio, continuam optando por ingressar em cursos de licenciatura. Nossa questão de pesquisa foi sobre quem, nos dias de hoje, quer ser professor ou professora?

Ao abordar o processo histórico de profissionalização do professorado em Portugal, Nóvoa (1999) desenvolve a evolução da profissão, desde ser exercida por religiosos até a sua forte intencionalidade política. Para Barreto (2010), a profissão docente comporta, ao menos, três representações: o magistério enquanto vocação, em virtude da concepção de educação como arte - o professor é um aprendiz que aprende com o Mestre; o magistério como profissionalismo, decorrente da necessidade de a escola transmitir a racionalidade científica, tendo o professor de assumir a postura de profissional do ensino; o magistério visto como um trabalho assalariado, em consequência da massificação do ensino e da deterioração das condições de trabalho, do salário e do prestígio docentes. Segundo pesquisa da Fundação Carlos Chagas (RIBEIRO, 2011), apenas 2\% dos jovens universitários desejam cursar licenciatura. Esse desinteresse pelo magistério já tem se refletido, por exemplo, na carência de profissionais qualificados para atuação em diversas áreas.

Agravando mais esse quadro, encontra-se o alto índice de abandono da profissão. Além das desestimulantes condições das escolas públicas, carentes de infraestrutura e gestão adequadas, uma das razões para esse abandono, segundo pesquisa realizada pela USP (TAKAHASHI; BEZERRA, 2011), é a média salarial percebida pelos docentes que atuam no ensino fundamental, inferior à média que recebem profissionais para os quais o ensino superior não é uma exigência. Em Fontoura (2011b), encontramos o reconhecimento de que a carreira docente requer uma renovação diária da escolha pelo magistério, uma vez que vai na contramão dos valores da sociedade moderna, como ganhar dinheiro ou ser individualista, contrários a uma vida dedicada ao outro, como aprendente, e a si como ensinante.

De acordo com Freire (2001, p. 40), não se nasce para ser professor ou professora, nem marcado para sê-lo. Confessa o autor, no entanto, que, desde menino, em seus 'sonhos', muito raramente não se via "encarnando figura que não fosse a de professor". Assim como o autor, muitas pessoas que optaram pela profissão docente costumam relatar histórias que justificam a escolha que fizeram. Barreto (2010), valendo-se de dados levantados pelo 
SOLETR

R $\quad$ E

T A Estudos Linguísticos - N. 27 - 2014.1 - Helena Fontoura e Neiva Fernandes

ENADE 2005 (Exame Nacional de Avaliação de Desempenho dos Estudantes), informa que cerca de $40 \%$ dos estudantes selecionados para a realização das provas declararam possuir renda familiar entre 0 e 3 salários mínimos. Isso é revelador: a escola, com a democratização do ensino, não só vem atendendo à demanda proveniente das camadas mais populares, mas grande parte dessa demanda tem chegado à Universidade, aos cursos de formação de professores. Observada a escolaridade dos pais desses licenciandos, a autora constatou que menos de $1 / 4$ possuíam o ensino médio e apenas $10 \%$ tinham diploma de graduação, ou seja, os candidatos seriam, na sua maioria, a primeira geração com acesso aos níveis superiores de instrução nas suas famílias.

Ainda que tenhamos claro que a formação inicial representa apenas um componente ou uma das etapas de um longo, contínuo e sempre inacabado processo de formação e de profissionalização docente, é justamente ela que exerce um dos papeis fundamentais nessa trajetória. Vidal (2010, p. 713) afirma que "antes de se tornarem professores, os sujeitos constituíram-se como alunos". Acrescenta que esse pressuposto conduz a alargar para todo o período passado nos bancos escolares a construção de uma ou várias referências de professor, compreendendo a escola como lugar amplo de difusão de modelos culturais, por exemplo, os modelos (positivos e negativos) de docência. No entanto, é durante o curso de licenciatura que o futuro professor entra em contato com uma série de conhecimentos fundamentais ao exercício da profissão. Acompanhando Tardif (2010), diríamos que cabe aos cursos de formação inicial docente proporcionar aos licenciandos a oportunidade do aprendizado de saberes disciplinares (que são os saberes sociais, correspondentes aos diversos campos do conhecimento) e saberes oriundos das ciências da educação e da ideologia pedagógica (que são os saberes da formação profissional, transmitidos pelas instituições formadoras).

Em uma profissão como a docência, baseada na interação humana, a dimensão pessoal do trabalhador se converte em um elemento fundamental para o desempenho de suas funções, que passam, necessariamente, pela interação com as demais pessoas à sua volta, principalmente, com os alunos (TARDIF, 2010). É nesse mesmo pensar que Freire (1996, p. 114) nos faz um alerta: "Não importa com que faixa etária trabalhe o educador ou a educadora. O nosso é um trabalho realizado com gente, miúda, jovem ou adulta, mas gente em permanente processo de busca". Defendendo que o 'ser professor' e o 'ser' professor são coisas intimamente relacionadas e indissociáveis, Nóvoa (1998) reflete a respeito dessa unidade, não apenas perceptível, mas necessária à prática docente, ao afirmar que é impossível separar o eu profissional do eu pessoal na docência. Como a profissão é uma 
SOLETR

importante dimensão da identidade dos indivíduos (DUBAR, 2005), a sua escolha, por si só, já representaria uma significativa etapa no processo de construção da identidade individual. E é nesse sentido que a instituição formadora do futuro docente possui uma grande responsabilidade: a de construir "as bases sobre as quais se edificará a identidade do futuro professor, com vistas à sua inserção crítica e competente no seio de uma sociedade marcada por profundas contradições e injustiças sociais" (SOUZA; FERREIRA, 2001, p. 31).

A Faculdade de Formação de Professores (FFP) da Universidade do Estado do Rio de Janeiro (UERJ), nosso campo de pesquisa, localiza-se no bairro do Patronato, em São Gonçalo, leste da Região Metropolitana do Rio de Janeiro. O município é um dos mais populosos do Estado, situado, em sua maior extensão, às margens da Baía de Guanabara (NUNES, 2010). A FFP é a maior unidade externa da UERJ e primeira instituição de ensino superior pública e gratuita instalada na cidade, dedicando-se, desde a sua criação, em $1973^{3}$, “à formação de professores para a Educação Básica e à produção de conhecimento em vários campos científicos" (UERJ/FFP, 2010).

Numa área de $44.000 \mathrm{~m}^{2}$ encontra-se instalado o campus da FFP. Esse espaço abriga cerca de 3.500 estudantes (UERJ/FFP, 2010), somando-se o quantitativo dos cursos de Graduação (sete) e de Pós-Graduação: Especialização (dez) e Mestrado Acadêmico (quatro), atualmente existentes ${ }^{4}$. A cada ano letivo, a FFP/UERJ oferece, através de concurso vestibular, um total de 660 vagas para ingresso em um de seus seis cursos: Ciências Biológicas, Geografia, História, Letras (habilitação em Português-Inglês ou PortuguêsLiteraturas), Matemática e Pedagogia (UERJ, 2011a).

$\mathrm{Na}$ construção da investigação exploratória, de caráter quali-quantitativo (FERNANDES, 2013), utilizamos questionários como instrumento de coleta. Foram convidados a participar estudantes inscritos em períodos específicos, no primeiro semestre letivo de 2012, e aplicados mais de 450 questionários, todos em presença de uma das autoras, após contato com os docentes responsáveis pelas turmas, que nos cederam espaço e tempo de suas aulas para esse fim. É importante ressaltar a atitude colaborativa de todos durante essa fase do trabalho.

Caminhamos norteadas por três eixos de análise: Opção pela licenciatura caracterizar o alunado da FFP/UERJ; saber os motivos que levaram a ingressar em cursos de formação para a docência; Visão acerca do curso e da formação inicial - perceber a visão que os participantes na pesquisa têm da formação que buscam receber e que vêm recebendo na

\footnotetext{
${ }^{3}$ Tendo completado 40 anos em 2013, dos quais 26 integrada à UERJ.

${ }^{4}$ Dados de 2012 
Faculdade; Profissão docente - conhecer sua visão a respeito do profissional professor e da profissão docente; ter noção das expectativas e intenções desses futuros professores quanto a vir a exercer ou não o magistério.

A análise foi feita utilizando a tematização proposta por Fontoura (2011a) que permite um melhor entendimento e uma sistematização do material levantado durante o processo de construção de pesquisas de caráter predominantemente qualitativo ou, como era o caso de nossa investigação, de cunho quali-quantitativo, com perguntas abertas e fechadas. Neste artigo, abordaremos aspectos relacionados ao primeiro e ao terceiro eixos, respectivamente, opção pela licenciatura e intenções dos estudantes da FFP/UERJ UERJ quanto a exercer ou não o magistério como profissão.

Das 660 novas vagas oferecidas, anualmente, pela FFP/UERJ, através de concurso vestibular, 450 delas estão representadas pelos sujeitos que aceitaram o convite à participação na pesquisa. Não há estrangeiros entre os participantes, todos que informaram a nacionalidade se declararam brasileiros $(83,1 \%)$ e a maioria dos licenciandos $(68,2 \%)$ se encontra na faixa etária de dezoito a 24 anos - todavia houve o registro de seis estudantes entre cinquenta e sessenta anos de idade: metade deles já se encontra no final de curso, concluindo História; os demais ou estão iniciando Pedagogia ou em sua fase intermediária: esses dois cursos parecem ter a preferência dos mais vividos. A maioria é do sexo feminino $(65,1 \%)$ - alargando-se esse quantitativo nos cursos de Letras (86,6\%), Pedagogia (85,7\%) e C. Biológicas $(74,5 \%)$ - e solteira (quase $80 \%$ ): o maior percentual de casados, nas graduações em geral, encontra-se em Pedagogia (38,5\%), seguido dos 15,7\% dos licenciandos de História, cursos nos quais, como já observado, encontra-se o grupo mais numeroso entre os estudantes das faixas etárias mais elevadas.

A Faculdade de Formação de Professores da UERJ, principalmente com o desenvolvimento de projetos de pesquisa e extensão e a consolidação de seus cursos de pósgraduação (lato e stricto sensu), vem se firmando como importante polo universitário na cidade de São Gonçalo, "estendendo sua área de abrangência para os municípios vizinhos - a leste da Baía de Guanabara" (UERJ/FFP, 2010): mais da metade dos licenciandos da FFP $(54,4 \%)$ reside em São Gonçalo; 38,7\% moram em outras cidades, totalizando os $93,1 \%$ que preencheram o campo no questionário. Um total de vinte municípios teve o seu nome informado nos questionários. A vizinha Niterói é a cidade da qual, dentre as demais, provém o maior percentual de estudantes: $15,8 \%$. Seguem-se, ainda: Rio de Janeiro (8,2\%), Itaboraí $(4,4 \%)$, Maricá $(3,3 \%)$ e Rio Bonito $(1,5 \%)$. 


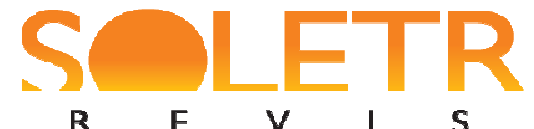

$\mathbf{R}$
S
T A

Nenhum dos participantes deixou de responder à pergunta: "Em sua família direta (pais e irmãos) há quem já tenha tido acesso ao nível superior?”. Logo, os percentuais são bastante representativos como indicadores importantes da bagagem cultural familiar da comunidade discente da FFP/UERJ. Em estudo realizado por Gatti e Barreto (2009), cerca de $10 \%$ dos licenciandos que participaram do ENADE 2005 tinham pais com escolaridade superior. Esse percentual, em nossa investigação, apresenta dado bem mais expressivo: 55,1\% do total de sujeitos já possuem, na família, pessoas com formação superior. Buscando relacionar, ainda, a questão do acesso à educação superior com os estudantes que residem no município de São Gonçalo, constata-se que apenas nos cursos de C. Biológicas $(52,2 \%)$ e Geografia (53,2\% - considerados ambos os turnos) o percentual dos que ainda não possuem, na família, diplomados em nível universitário é superior ao do grupo dos que já possuem. Dessa forma, não há como deixar de reconhecer o já mencionado importante papel da Faculdade de Formação de Professores em São Gonçalo.

A fim de preservar anônima a identidade dos 'sujeitos-cúmplices' (TAVARES, 2008a), participantes na pesquisa, foi realizada a codificação alfanumérica de cada um, composta: pelas letras iniciais de cada curso (CBIO, GEO, HIS, LET, MAT ou PED); pela especificação do turno (mt, tn, ma ou no); pela habilitação (ING ou LIT); pela identificação do momento do curso em que o estudante se encontrava (I, M ou F) e por um algarismo arábico sequencial.

As respostas à pergunta Por que você decidiu fazer uma licenciatura? foram revelando justificativas para a decisão e uma declarada intenção do participante que trazia variações entre 'ser professor' e 'não ser professor'. Percebeu-se que entre os 450 participantes no estudo, há estudantes: que parecem 'querer ser professores'; que parecem 'não necessariamente, querer ser professores'; que 'não pensavam em ser professores, mas...' resolveram experienciar a licenciatura ou aproveitar a classificação no vestibular; que declaram 'não querer ser professores' e aqueles que decidiram 'silenciar' diante da pergunta ou não tiveram suas respostas devidamente compreendidas. A partir das respostas, destacaram-se dois dos patamares: aquele que congrega os sujeitos que declararam querer (ou parecem querer) ser professores $(42,9 \%)$ e aquele que categoriza as respostas que, em princípio, não revelaram, exatamente, se os estudantes pretendem ou não exercer a profissão (40,2\%). Dentre os vários motivos apresentados pelos participantes do primeiro dos patamares, para justificar a sua decisão de realizar uma licenciatura, estão a identificação com a docência $(51,8 \%)$ (através do sentimento de vocação ou não); a vontade de lecionar $(18,6 \%)$; a intenção de (trans)formar ou influenciar indivíduos e a sociedade em geral $(7,3 \%)$ : 
A profissão de professor é uma das mais dignas e tem todo o amor pelo curso escolhido: no momento não me veria fazendo nada além da licenciatura. (GEOmt - I, 20).

Eu sempre sonhei em ser professora, e minha mãe já é professora e tinha uma escola de fundo de quintal, sempre a ajudava. Nunca me vi em outra profissão sem ser a de lecionar em sala de aula com crianças. (PEDno $-\mathrm{I}, 13)$.

Desde criança tive vontade de ser professor. Penso que é interessante a construção do conhecimento, a sua transmissão. (HIS - M, 11).

Porque ser professor de ciências é algo que eu trago comigo desde pequeno, além de gostar muito da mesma. (CBIO - F, 10).

Palavras como 'sempre', 'desde', 'nunca', associadas a 'sonho', 'paixão' e derivadas compuseram a grande maioria dos segmentos de textos construídos pelos licenciandos em relação, principalmente, às categorias identificação e vontade, conforme exemplificações acima. Ainda com Freire (1996, p. 142), percebem-se presentes nessas declarações tal 'força misteriosa', por vezes, diz o autor, 'chamada vocação' que move, impulsiona e faz permanecer no magistério a grande maioria dos professores - "apesar da imoralidade dos salários".

Um grande desejo de colaborar para uma mudança, uma transformação $(7,3 \%)$ da sociedade foi declarado, principalmente, pelos ingressantes em História e Geografia: um claro reconhecimento do papel político da profissão e de sua assunção pelo sujeito, futuro professor:

Decidi fazer uma licenciatura por acreditar que desta forma poderei ter contato com jovens estudantes e ajudálos a formar um pensamento mais crítico com o mundo. Por acreditar que a mudança está na educação. (GEOmt - I, 18).

Porque eu quero ter a oportunidade de fazer a diferença na vida de outros jovens de forma positiva $e$ incentivadora. (GEOtn - I, 7).

Decidi fazer história porque vejo no professor a figura de alguém que realmente pode mudar o mundo. (HIS - I, $15)$.

'Fazer a diferença' foi uma expressão inúmeras vezes utilizada nas respostas aos questionários: existe, nela contida, uma espécie de sentimento romântico de crença no poder de intervenção individual. Ao mesmo tempo em que, na expressão freireana, essa 'força misteriosa' impulsiona o indivíduo a seguir em frente, a superar possíveis obstáculos ao longo de seu curso e/ou de sua carreira, parece-nos que a instituição de ensino responsável pela formação inicial precisa estar atenta à 'dosagem' equilibrada disso tudo, sob pena de os profissionais nela formados idealizarem sua capacidade individual de atuação, não prevendo a heterogeneidade e os possíveis conflitos e dilemas a serem enfrentados e perdendo a dimensão coletiva do exercício docente. Discutindo a esse respeito, Esteve $(1999$, p. 109) alerta para o 
fato de que, muitas vezes, "o professor novato sente-se desarmado e desajustado ao constatar que a prática real do ensino não corresponde aos esquemas ideais em que obteve a sua formação".

As relações interpessoais (5,2\%), componente invariavelmente presente e determinante em um processo pedagógico, conforme nos lembra Fontoura (2008), e a contribuição, ajuda $(3,1 \%)$ mereceram, igualmente, referência nas respostas dos participantes que declararam os motivos de sua opção pela licenciatura:

Porque eu tenho um filho de 8 anos e quase não entendo ele: quero conhecê-lo melhor e educá-lo melhor. Acredito que é na escola, com professores, que vou crescer como pessoa e aprender a me conhecer e a educar pessoas. (PEDno - I, 22).

Posso contribuir e muito para o futuro do nosso país e principalmente para a comunidade onde vivo. (GEOmt I, 32).

Para contribuir com a educação em nossa cidade. (L(LIT) - I, 1)

Porque acredito no que faço, no ser humano e que sou capaz de contribuir para a formação pessoal e profissional de outrem. (PEDma-M, 13).

Constata-se, pelos segmentos, o sentimento de integração do sujeito à cidade, à comunidade onde vive e o seu desejo de colaborar com as individualidades que as compõem.

Outro percentual considerável de respostas (40,2\%) compôs o segundo dos patamares, e não deixou clara a intenção do sujeito em seguir a carreira docente: as razões mencionadas em função da decisão de cursar uma licenciatura tanto poderiam indicar a pretensão de exercer a profissão professor como não. Nesse patamar, destacaram-se as categorias: ingresso no (ou acesso ao) nível superior de ensino, com 32,6\% de ocorrências, acesso ao mercado de trabalho (22,1\%), localização da FFP (14,9\%) e baixa concorrência (12,2\%), referindo-se à relação candidato-vaga para os cursos de licenciatura no vestibular.

Porque tenho vontade de seguir a vida acadêmica, pretendo fazer mestrado e doutorado para lecionar em uma universidade. (CBIO - M, 8).

Já sou professora há 22 anos (antigo normal), quero trabalhar com coordenação e aprimorar meus conhecimentos. (PEDma-M, 5).

As motivações dos estudantes para ingressar em uma instituição de ensino superior vão desde o desejo de continuidade dos estudos até a pretensão de promover o auto aperfeiçoamento ou atualização, uma vez que muitos já são profissionais do ensino. $\mathrm{O}$ alto índice de empregabilidade da profissão, a intenção de realizar concursos públicos (relacionados ao magistério ou não), as 'flexibilidades' inerentes à carreira e o desejo de mudança de área profissional, moveram o conjunto de estudantes que visam ao mercado de trabalho $(22,1 \%)$. 
Porque é uma área interessante e não vou ficar desempregada (pelo menos eu acho).(GEOtn - I, 12).

Boas oportunidades no mercado de trabalho. (MAT - I, 4).

Para concursos públicos, passando eu teria tempo de lecionar e me dedicar aos concursos. (PEDno - I, 2).

Primeiro, por querer mudar de área profissional (comércio) e, segundo, por planejamento pessoal em relação a filhos. (PEDma - I, 24).

Um dos participantes na pesquisa (PEDma - I, 24) acrescenta, à pretensão de mudança de área profissional, a questão do planejamento familiar, atraindo, também, a atenção para uma das características consideradas positivas da profissão: a sua flexibilidade de horários e jornadas. Conforme já mencionado, constatou-se que residem no município de São Gonçalo, onde está localizada a FFP/UERJ, 54,4\% dos licenciandos que participaram da pesquisa. Não se tratou, então, de nenhuma novidade a figuração, entre as razões que motivaram o estudante a decidir fazer um curso de licenciatura na Faculdade, da categoria localização da FFP $(14,9 \%)$ - e não se pode ignorar, inclusive, que a unidade da UERJ representa a única alternativa de vagas em instituição pública de ensino presencial na populosa cidade.

Decidi fazer em SG [São Gonçalo] por questão de localidade. Não foi uma escolha direta para a licenciatura. (GEOtn - F, 14).

Escolhi a FFP pela proximidade da minha casa. Nunca tive a licenciatura como primeiro plano. A ideia de exercer a profissão veio com o tempo e com o curso. (HIS - M, 6).

Segundo pesquisa realizada por Zago (2006, p. 229), “comprovadamente, não há relação direta entre as características socioculturais da família e a aprovação no vestibular, pois a maioria dos candidatos é reprovada em decorrência da distorção demanda/oferta de vagas"; entretanto, para a autora, quando considerados a origem social e o passado escolar dos inscritos e aprovados, "os resultados evidenciam a forte desigualdade de acesso ao ensino superior e a seletividade fundada na hierarquia dos cursos universitários". Percebendo essa relação, muitos dos sujeitos no estudo indicaram a baixa concorrência $(12,2 \%)$ para os cursos de licenciatura como o motivo para a sua escolha:

Pela afinidade com a disciplina e por ter relação candidato/vaga menor do que o Bacharel. (GEOmt - M,10).

Porque era o curso no qual eu achava que tinha mais chances de conseguir entrar. (HIS - I, 14).

Tardif (2010), citando Atkinson \& Delamont (1985), chama a atenção para uma ideia, apontada pelos autores: a do "autorrecrutamento" para o magistério. Segundo o que notaram, apesar de a experiência pessoal na escola exercer influência significativa na opção pela docência, essa experiência "seria menos importante do que a de ter parentes próximos na área da educação, o que refletiria um recrutamento [...], pela observação, em casa, do habitus familiar" (TARDIF, 2010, p. 76). Menciona, ainda Tardif, certos relatos espontâneos de 
$\mathbf{R}$

docentes, durante pesquisa realizada, referindo-se à influência de seus antigos professores na opção por sua carreira e no seu modo de ensinar. Da mesma forma, em nosso estudo, relataram que sofreram influência de familiares e/ou de professores e se apoiaram em modelos e exemplos $8,8 \%$ e $6,1 \%$, respectivamente, do total de estudantes participantes na investigação. Notou-se que os estudantes de Geografia são os que trazem o maior número de modelos/exemplos inspiradores para tal decisão.

De certa maneira, por afinidade e influência da família. (GEOmt - I, 23).

Ótimas influências de professores do curso preparatório. (GEOtn - I, 5).

Descobri durante a minha vida profissional que gostava de escola. E tenho uma inspiração por minha mãe/professora do $1^{\circ}$. [Segmento] do fundamental. E meu pai, por ser semianalfabeto. (PEDma - F, 5).

Embora com uma representação pouco expressiva - apenas 3,3\% do total de graduandos relacionados ao patamar -, a categoria perspectivas de futuro melhor aponta para o papel que a licenciatura pode assumir como uma segunda atividade ou como promotora de oportunidades. As respostas a seguir colocam essas questões:

Decidi, pois seria uma forma de melhorar minha renda, pois sou militar e sendo também professor posso dar aula no período noturno. (MAT - I, 6).

Para conseguir um futuro melhor e ajudar minha mãe. (PEDno - I, 4).

Cerca de $11 \%$ dos licenciandos da FFP/UERJ indicaram a existência de um terceiro patamar, quando declararam que não decidiram, propriamente, fazer uma licenciatura, contingências os teriam levado a tal situação:

Na verdade não queria fazer licenciatura, queria o bacharelado, mas passei para a FFP e decidi descobrir o mundo da licenciatura. (CBIO - I, 5).

Tive vontade de ver como é ser professor. (GEOmt - M, 5).

Não decidi, foi a faculdade para a qual passei. (HIS - F, 9).

Na verdade não decidi, aconteceu. Pensei que não fosse passar no vestibular e também não era o que eu queria, mas passei e não desperdicei a chance. (L(ING) - I, 6).

Oportunizar ou experienciar a licenciatura e/ou a profissão docente $(18,4 \%)$, ou, ainda, usufruir da aprovação no vestibular (51\%), mesmo que não fosse essa a sua primeira opção, foram motivos apontados para o ingresso de muitos dos estudantes nos cursos da FFP.

Com base na análise das respostas à pergunta Por que você decidiu fazer uma licenciatura?, foi possível identificar um total de 4,2\% de rejeição declarada ao exercício da profissão docente, para a composição de novo patamar: a pretensão de fazer (ou mudar para) o bacharelado (57,9\%), a de seguir outra carreira (10,5\%) ou o desejo de enfatizar a 
$\mathbf{R}$

E $\quad \mathrm{I}$

T A

Estudos Linguísticos - N. 27 - 2014.1 - Helena Fontoura e Neiva Fernandes

formação teórica (5,3\%), para seguir no ramo da pesquisa, foram as categorias que organizaram, por exemplo, as respostas a seguir:

Na verdade quero bacharelado, não pretendo dar aula. (GEOmt - I, 28).

Minha intenção não era fazer uma licenciatura, pois quero ingressar na Marinha Mercante, o que é, hoje, meu principal objetivo. (MAT - I, 3).

Na verdade, não pretendo seguir nessa área. Prefiro a área de pesquisa etc.. (CBIO - I, 23).

No estudo desenvolvido por Gatti e Barreto (2009), foi indagado aos estudantes no ENADE 2005 a principal razão de sua opção pela licenciatura. Em nossa pesquisa, utilizamos uma questão aberta para perguntar o porquê dessa decisão, permitindo que o sujeito se colocasse da maneira como lhe conviesse. O painel de motivos revelados foi extenso, possibilitando o conhecimento mais aprofundado dos participantes e das intenções que os moveram. Aos graduandos que ainda não exerciam a profissão $(21,8 \%$ do total de participantes já a exerciam), foi perguntado se pretendiam exercê-la. À pergunta foram oferecidas duas opções de resposta - 'não' ou 'sim' - e um convite ao comentário sobre os motivos da resposta. Pelo exame dos questionários, observou-se que uma terceira resposta foi oferecida pelos estudantes: NTC ('não tenho certeza'):

Sim, mas eu ainda não tenho tanta certeza, pois eu quero trabalhar com genética também; então, não posso responder isso agora. (CBIO - I, 17).

Por enquanto não a exerço, mas se um dia vier a exercê-la vai ser somente quando melhorar o nível salarial. (MAT - M, 1).

Ainda não decidi, porque eu ainda não tive experiência em sala de aula. (L(LIT) - F, 5) .

Quero exercer por gostar do fato de estar passando conhecimento para o próximo, para ajudar na formação de outrem. Não quero exercer devido aos 'perrengues' conhecidos da profissão, do dia a dia em sala de aula. (L(LIT) - F, 6).

Talvez. No momento participo de um projeto de iniciação à docência e estou construindo uma visão quanto ao meu desejo de atuar dentro de sala de aula. (PEDma - M, 10).

No geral, apenas 5,3\% dos participantes na pesquisa comentaram que ainda não têm certeza se pretendem, de fato, exercer a docência. Os motivos são variados: a preferência pela área de pesquisa; a insatisfação com a remuneração da carreira, as condições de trabalho e as especificidades do ofício; a experimentação, ainda não vivenciada, do contato com a sala de aula. Considerados os três momentos dos estudantes nos cursos, percebeu-se que o maior nível de indecisão se concentrou na fase intermediária: 7,2\%. Entre os licenciandos de Matemática nessa fase, um terço deles declarou 'não ter certeza ainda'. Entre os graduandos em Letras (LIT), os percentuais também foram bastante expressivos - tanto no meio $(22,2 \%)$ quanto no final de curso $(37,5 \%)$. 
$\mathrm{S}_{R} \mathrm{E}_{\mathrm{E}} \mathrm{L}_{V} \mathrm{ET} \mathrm{T}_{\mathrm{s}} \mathrm{R}$

Afirmaram que não pretendem exercer a profissão $18 \%$ dos licenciandos da FFP/UERJ participantes na pesquisa. Constatou-se, no entanto, que havia um declínio progressivo $(20,3 \% ; 17,1 \% ; 14 \%)$, respectivamente, do percentual de rejeição ao magistério à medida que os estudantes avançam nos cursos; o número de alunos também decresce. De qualquer modo, entre os ingressantes - com exceção para os estudantes de Ciências Biológicas $(58,1 \%)$ que responderam não pretender exercer a docência -, a média de 20,3\% não é muito elevada. Isso significa que quase $80 \%$ daqueles que ingressaram, em 1/2012, nos cursos da Faculdade têm ou podem vir a ter (considerando os ainda indecisos) a intenção de atuar como professor/a.

Um segundo percentual de rejeição ao magistério entre os ingressantes foi o de $25 \%$ identificados no curso de Pedagogia (no). Entre aqueles que iniciavam os seus cursos, os estudantes de Letras (LIT) e os de Matemática ofereceram os menores percentuais $(4,8 \%$ e $7,7 \%$ - respectivamente) de respostas negativas. Os motivos para justificar a não pretensão de exercer o ofício docente foram relacionados à preferência pelas atividades de pesquisa ou por outra carreira, em geral, a ser proporcionada por futuro bacharelado; à ausência de vocação; às condições de trabalho pouco atraentes - especialmente, as salariais; a aspectos pessoais os de personalidade - ou a experiências que marcaram negativamente o sujeito; ao fato de já se encontrar inserido no mercado de trabalho - em outro ramo ou atividade, conforme alguns comentários transcritos a seguir:

Não, pois não tenho vontade de exercer o magistério: prefiro a área de pesquisas. (CBIO - I, 5).

Não acredito ter vocação para tal e a desvalorização do profissional também é um fator importante. (GEOmt I, 12).

Pretendo fazer bacharelado e trabalhar como geógrafo. (GEOmt - M, 1).

Não pretendo exercer. Quero atuar na área de revisão de textos. (L(ING) - M, 2).

Sou funcionário público militar há dezesseis anos, aprovado em um concurso que, na época, exigia apenas o $1^{\circ}$. Grau [Ensino Fundamental]. Ainda assim, ganho o triplo do que ganha um professor. (PEDno - M, 05).

Trabalhei como professora em cursos e uma escola e não tive boas experiências. Ao trabalhar em empresas, percebi que me agradava mais. (L(ING) - F, 12).

Vergonha e timidez. (MAT - F, 4).

Iniciando, passando pela fase intermediária da graduação ou concluindo o seu curso, quase um quinto dos estudantes parece estar convicto da decisão que socializou. Foi surpreendente o percentual de estudantes que se posicionaram afirmativamente diante da pergunta: Se ainda não exerce a profissão docente, pretende exercê-la?: $76 \%$ dos participantes disseram que 'sim'. Entre os ingressantes, o percentual é de 73,7\%, chegando a $81,3 \%$ no grupo dos que concluíam a licenciatura no ano letivo de 2012. É importante 
ressaltar que, entre os que responderam 'Sim', está sendo considerado, também, o quantitativo de participantes que declararam, em outro item do questionário, que já exerciam a profissão professor/a. Entre os graduandos que iniciavam os seus cursos, com exceção daqueles estudantes de C. Biológicas $(38,7 \%$ ) e Pedagogia (no - 6,7\%), os percentuais relativos à resposta afirmativa alcançaram, ao menos, 75\%: praticamente, a média geral. O destaque positivo se refere ao curso de Letras (LIT): $90,4 \%$ de seus ingressantes afirmaram pretender exercer a profissão docente. Seguem-se, a esse curso, Pedagogia (ma - 85,2\%) e Matemática $(80,8 \%)$. Já nas duas outras fases, sobressaem positivamente os cursos de História $(88,2 \%)$, Geografia (mt - 93,3\%) e C. Biológicas $(91,7)$, esses dois últimos, na fase conclusiva das graduações.

Em seguida, alguns dos motivos dados pelos licenciandos para justificar o 'sim' de sua resposta:

Sempre gostei, desde criança, de brincar de dar aula. Além disso, tenho muitos professores na minha família que amam o que fazem. (CBIO - I, 12).

Boa remuneração e vocação. (GEOmt - I, 4).

Eu sempre quis ser professora e não me vejo fazendo outra coisa além do magistério. (GEOmt - I, 11).

Pretendo lecionar porque acredito que o professor tem um papel fundamental na formação social do cidadão e desejo ser uma influência positiva para os meus alunos. (GEOtn - I, 7).

Caso atue como professora, gostaria de ser do modo que os professores que tive nunca foram. (PEDma - I, 2).

Durante a faculdade, desenvolvi a vontade de dar aula: nunca tive tanto interesse na área da educação - não como tenho hoje. (HIS - M, 6).

Pretendo lecionar para o ensino médio e superior; no entanto, não pretendo fazer dessa a minha atividade principal. (L(ING) - M, 9).

Sim, pois é o que pretendo desde o início da minha graduação. Quero ser professora, quero poder transmitir para os meus alunos um ensino mais significativo, que faça sentido para o aluno. (L(LIT) - M, 6).

Gosto de ensinar e mais ainda a Matemática. Hoje, trabalho com Informática porque preciso. Quero ensinar Matemática por gosto. Ainda não sei se manterei as duas profissões. (MAT - M, 2).

Pretendo atuar como professora universitária e também para crianças na área de Matemática; porém, este último, será por pouco tempo, apenas para obter experiência escolar. (PEDno - M, 7).

[...], o curso de Biologia numa faculdade de formação de professores me fez abrir os olhos para uma aptidão que eu não conhecia em mim; por isso, ainda quero ter essa vivência. (CBIO - F, 4).

Com certeza vou exercer, porque tenho vontade de fazê-lo. Apesar das condições de trabalho não serem atrativas, sinto que é algo que nasci para fazer. (GEOmt - F, 13).

Pretendo exercê-la no nível universitário, mas também atuar no ramo de pesquisas. (MAT - F, 5).

Embora não se nasça, exatamente, professor ou professora (FREIRE, 2001), muitos estudantes comentaram a respeito de sua vocação ou de suas aptidões 'natas'. O elemento 


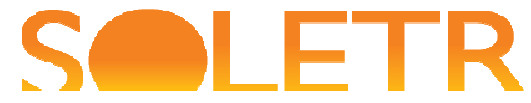

$\mathbf{R}$

‘vocação' não é inconciliável com o conceito de profissão. Outros graduandos mencionaram a pretensão de exercer a docência, sim, mas por um período experimental, temporário, não como atividade principal. Promover um 'ensino mais significativo', ser 'diferente' dos professores que teve, lecionar 'por gosto'... A indagação a que o conjunto dos licenciandos respondeu foi se pretendia exercer a profissão: $76 \%$ disseram que sim.

Sabemos que, para os iniciantes, ainda havia um curso inteiro pela frente; para aqueles da fase intermediária, ainda um bom caminho a percorrer; para os concluintes, um grande desafio: os primeiros anos de inserção profissional representam um período decisivo (CAVACO, 1999) para a vida do recém-formado professor: toda a adaptação necessária à nova realidade não será fácil. Trata-se, como afirma Tardif (2010, p. 83), de uma espécie de "rito de passagem da condição de estudante à de professor" - necessário e imprescindível para a constituição da importante dimensão da identidade dos indivíduos que corresponde à escolha profissional e à sua 'identificação' com ela (DUBAR, 2005).

À guisa de conclusão, trazemos que o presente artigo tratou de dar a conhecer alguns dos resultados do estudo construído em Fernandes (2013): mais especificamente, àqueles relacionados ao tema "Opção pela Licenciatura" e às intenções dos 450 licenciandos da Faculdade de Formação de Professores (FFP) da Universidade do Estado do Rio de Janeiro (UERJ), participantes na pesquisa, quanto a exercer ou não a profissão docente. Dentre uma série de informações e contribuições relevantes, a pesquisa constatou que expressivos $55,1 \%$ do total de sujeitos no estudo já possuem, na família, parentes em linha reta, de primeiro grau (pais ou filhos), mas também de segundo grau (irmãos) com instrução superior: isso parece refletir a positiva imagem da ação educacional, também, da Faculdade no município - já que na cidade de São Gonçalo há outras instituições de ensino superior.

Partindo da sistematização dos dados sugerida por Fontoura (2011a), utilizamos a Tematização para o tratamento das respostas dos estudantes às perguntas abertas dos questionários. Os motivos declarados mostram que uma parcela muito significativa tem optado pela realização de uma licenciatura na FFP pelo sentimento de identificação, de vocação - por vezes, 'um sonho', e desde 'criança' - pela docência: percebe uma aptidão pessoal para exercê-la. Esse grupo declara ter como objetivo concluir o curso, diplomar-se professor e, para além do desejo de transmitir conhecimentos, contribuindo com a educação formal de seus futuros alunos, vir a influenciar de forma positiva esses alunos, tentando promover a sua transformação, colaborando na construção de cidadãos críticos e conscientes de suas necessidades e potencialidades. O estudo mostra, dessa forma, que, embora a 
$\mathbf{R}$

E V I S

T

Estudos Linguísticos - N. 27 - 2014.1 - Helena Fontoura e Neiva Fernandes

profissão docente venha enfrentando um período de desprestígio social, desestimulando muitos a abraçarem a carreira, a busca pelo encontro de uma identidade profissional ainda tem movido estudantes que se percebem vocacionados e apaixonados pela docência.

A pesquisa permitiu ainda que se conhecesse outra parcela, também bastante expressiva, de sujeitos que, em princípio, não revelaram diretamente a 'opção pela licenciatura' como sinônima de 'opção pela docência': declarou esse grupo que sofreu influência de familiares docentes ou não - e de professores, que representam, em muitos casos, exemplos e modelos de como exercer o magistério como profissão. Realizar um curso de nível superior para um grande número de estudantes advém do desejo ou da necessidade de dar prosseguimento aos estudos - muitas vezes, iniciados no Curso Normal. Visam, também, ao ingresso no mercado de trabalho e/ou à sua valorização nele: a conclusão da licenciatura, em muitos casos, é a oportunidade de participar de processos seletivos públicos que demandem nível superior. A pesquisa mostrou, também, que mesmo não desejando ser professor, muitos reconhecem o alto nível de empregabilidade que um diploma de licenciatura oferece, permitindo o exercício da docência como segunda atividade; revelou, ainda, a concepção da licenciatura como possibilitadora de um futuro melhor.

O estudo indicou que, entre o alunado, muitos não lograram aprovação nos concursos vestibulares para os cursos que inicialmente desejavam: decidiram experienciar ou oportunizar a licenciatura. Ainda assim, parte desse grupo declarou que buscará o bacharelado na mesma área (imediatamente ou mais tarde), que pretende se dedicar à pesquisa ou que continuará insistindo na aprovação para o curso de interesse. Percebeu-se, portanto, que a oportunidade de acesso ao ensino superior público é fator determinante, em muitos casos, na decisão de realizar uma licenciatura.

A FFP/UERJ tem um papel fundamental nisso tudo: além de sua localização, mencionada - tanto pelos residentes nas circunvizinhanças, quanto por aqueles que provêm de cidades distanciadas de São Gonçalo - como motivo (senão principal, ao menos, relevante) para a decisão de fazer uma licenciatura e do fato de a concorrência ser menos acirrada do que nos cursos para bacharel, foi declaradamente escolhida em virtude de um manifesto reconhecimento à qualidade dos cursos ministrados, bem como à excelência de seu quadro docente.

Quanto à questão sobre a pretensão em exercer a profissão, um pequeno percentual $(0,7 \%)$ deixou de responder à indagação; apenas 5,3\% declararam-se indecisos - ainda não tinham certeza se exerceriam a docência - e expressivos $76 \%$ dos estudantes manifestaram-se 
afirmativamente a respeito, ou seja, menos de vinte por cento dos estudantes afirmaram que não pretendem exercer a profissão, o que potencializa a responsabilidade da instituição formadora desses licenciandos. Conhecendo algumas das características básicas dos estudantes da Faculdade de Formação de Professores da Universidade do Estado do Rio de Janeiro participantes na pesquisa, refletindo a respeito dos motivos de sua opção pela licenciatura e conhecendo a sua pretensão sobre exercer ou não a profissão, encontramos importantes perspectivas e contribuições para favorecer novas reflexões e ações propositivas no campo da formação inicial de professores e professoras nos cursos de licenciatura, desafios para quem forma professores para a educação básica.

\section{Referências}

ATKINSON, P.; DELAMONT, S. Socialization into Teaching: the research which lost its way. British Journal of Sociology of Education, 1985, v. 6, p. 307-322.

BARRETO, Elba S. de S. Trabalho docente e modelos de formação: velhos e novos embates e representações. In: DALBEN, Ângela et al. (Org.). Coleção Didática e Prática de Ensino: convergências e tensões no campo da formação e do trabalho docente: didática, formação de professores, trabalho docente. Belo Horizonte, MG: Autêntica, 2010, p. 288-306.

CAVACO, Maria Helena. Ofício do professor: o tempo e as mudanças. In: NÓVOA, António (Org.). Profissão professor. Lisboa: Porto, 1999, p. 155-191.

DUBAR, C. A socialização: construção das identidades sociais e profissionais. Trad. Andréa Stahel M. da Silva. São Paulo: Martins Fontes, 2005.

ESTEVE, José M. Mudanças sociais e função docente. In: NÓVOA, António (Org.). Profissão professor. Lisboa: Porto, 1999, p. 93-123.

FERNANDES, Neiva Santos Masson. Quem quer ser professor ou professora? Um estudo com graduandos dos cursos de licenciatura da Faculdade de Formação de Professores da UERJ. Dissertação (Mestrado em Educação) - Faculdade de Formação de Professores, Universidade do Estado do Rio de Janeiro, São Gonçalo, 2013.

FONTOURA, Helena Amaral. Analisando dados qualitativos através da tematização. In: FONTOURA, Helena Amaral da (Org.). Formação de professores e diversidades culturais: múltiplos olhares em pesquisa. Coleção Educação e Vida Nacional. Niterói, RJ: Intertexto, 2011a.

Percursos de formação e experiências docentes: um estudo com egressos do curso de pedagogia da faculdade de formação de professores da UERJ. In: FONTOURA, Helena Amaral da (Org.). Residência pedagógica: percursos de formação e experiências docentes na Faculdade de Formação de Professores da UERJ. Niterói, RJ: Intertexto, 2011 b. 
Formando professores que aprendem a partir dos relatos: uma experiência da Faculdade de Formação de Professores (FFP) da UERJ. Revista da FAEEBA: Educação e Contemporaneidade, Salvador, v. 17, n. 29, p. 137-146, 2008.

FREIRE, Paulo. Pedagogia da autonomia: saberes necessários à prática educativa. São Paulo: Paz e Terra, 1996.

FREIRE, Paulo. Política e educação: ensaios. 5. ed. São Paulo: Cortez, 2001.

FREITAS, Marilena Tiengo (Coord.). O que pensa da FFP a comunidade acadêmica. Relatório do Projeto, 1994, FFP/UERJ, s/referências adicionais (mimeo).

GATTI, Bernardete Angelina; BARRETO, Elba Siqueira de Sá (Coord). Professores do Brasil: impasses e desafios. Brasília, DF: UNESCO, 2009.

NÓVOA, António. (Org.). Profissão professor. 2. ed. Lisboa: Porto, 1999.

NÓVOA, António. Relação escola-sociedade: novas respostas para um velho problema. In: SERBINO, Raquel V. et al. (Org.). Formação de professores. São Paulo: Fundação Editora da UNESP, 1998, p. 19-39.

NUNES, Clarice (Org.). Docência e pesquisa em educação: na visão de Haydée Figueirêdo. Rio de Janeiro: Litteris Editora, 2010.

RIBEIRO, Marcelle. Pesquisa mostra que apenas 2\% dos jovens querem ser professores. Jornal O Globo, Rio de Janeiro, 14 nov. 2011.

SOUZA, Donaldo Bello de; FERREIRA, Rodolfo (Org.). Formação de professores na UERJ: memória, realidade atual e desafios futuros. Rio de Janeiro: Universidade do Estado do Rio de Janeiro, Faculdade de Educação, NUPE, 2001.

SOUZA, João Valdir Alves de. Quem ainda quer ser professor? Boletim da UFMG, Universidade Federal de Minas Gerais, Belo Horizonte, ano 38, n. 1755, 31/10/2011. Disponível em: <http://www.ufmg.br/boletim/bol1755/index.shtml>. Acesso em: 15 jun. 2013.

TAKAHASHI, Fábio; BEZERRA, Elton. $10 \%$ dos professores no país fazem 'bico'. Folha de São Paulo. Disponível (para assinantes) em: $<$ http://www1.folha.uol.com.br/fsp/cotidian/ff0711201110.htm>. Acesso em: $12 \mathrm{dez} .2011$.

TARDIF, Maurice. Saberes docentes e formação profissional. Petrópolis, RJ: Vozes, 2010.

TAVARES, Maria Tereza Goudard. Infâncias em periferias urbanas: textos, contextos e desafios para a formação das professoras da infância. In: GARCIA, Regina Leite; ZACCUR, Edwiges (Orgs.). Alfabetização: reflexões sobre saberes docentes e saberes discentes. São Paulo: Cortez, 2008, p. 109-127.

TEDESCO, J. C.; FANFANI, E.T. Nuevos maestros para nuevos estudiantes. In: Maestros en América Latina: nuevas perspectivas sobre su formación y desempeño. Santiago de Chile: Preal, Ed. San Marino, 2004. 
UNIVERSIDADE DO ESTADO DO RIO DE JANEIRO. Edital de convocação para o exame discursivo do vestibular estadual 2012. Anexo 2. Quadro de Cursos / Vagas. Rio de Janeiro, 2011a. <http://www.vestibular.uerj.br/portal_vestibular_uerj/index_portal.php>. Acesso em 06 out. 2011.

UNIVERSIDADE DO ESTADO DO RIO DE JANEIRO. Faculdade de Formação de Professores. Catálogo-observatório acadêmico-institucional da Faculdade de Formação de Professores. São Gonçalo, RJ, 2010.

VIDAL, Diana Gonçalves. A docência como uma experiência coletiva: questões para debate. In: DALBEN, Ângela et al. (Org.). Coleção Didática e Prática de Ensino: convergências e tensões no campo da formação e do trabalho docente: didática, formação de professores, trabalho docente. Belo Horizonte/MG: Autêntica, 2010, p. 711-734.

ZAGO, Nadir. Do acesso à permanência no ensino superior: percursos de estudantes universitários de camadas populares. Revista Brasileira de Educação, Campinas, v. 11, n. 32, p. 226-237, maio.-ago, 2006.

Who wants to be a teacher? Contributions on a study with graduate students at the Faculdade de Formação de Professores of the Universidade do Estado do Rio de Janeiro

\begin{abstract}
This article presents some of the results of a research performed in the Master's degree in Education with students of Faculdade de Formação de Professores (UERJ): characteristics of their profile, the motivations for entrance in training courses for the exercise of teaching and their claims as to engage in the teaching profession. Were invited to participate in the survey students enrolled in specific periods, with the intention of reaching students entering, half way and seniors from each of the courses in the institution. Paulo Freire, António Nóvoa, Maurice Tardif, Bernadette Gatti and Elba de Sá Barreto are some of the authors with whom we dialogue in our investigation. In this exploratory research, quali-quantitative approach, we use questionnaires as a tool for data collection. In all, 450 students participated in the study. From what was known, the analyses and reflections built, we seek to help FFP/UERJ to have subsidies for the construction process of its political pedagogical project, making it possible to improve their goals, which seems relevant in order to encourage reflection and discernment in its actions in the field of initial training of teachers in the institution.
\end{abstract}

Key words: Teaching profession. Professional choice. Teacher training.

Recebido em: 15 de maio de 2014.

Aprovado em: 01 de outubro de 2014. 